\title{
Modeling Control Methods to Manage the Sylvatic Plague in Black-Tailed Prairie Dog Towns
}

\author{
David C. Elzinga ${ }^{1, *}$, Shelby R. Stowe ${ }^{2}$, F. Leland Russell ${ }^{3}$ \\ ${ }^{1}$ Department of Mathematics, University of Tennessee, Knoxville, TN 37996 \\ ${ }^{2}$ Department of Mathematics \& Statistics, Colorado School of Mines, Golden, CO 80401 \\ ${ }^{3}$ Department of Biological Sciences, Wichita State University, Wichita, KS 67260 \\ delzinga@vols.utk.edu
}

Black-tailed prairie dogs (Cynomys ludovicianus) are a keystone species of shortgrass and midgrass prairies, making them essential for successful reintroduction efforts of endangered black-footed ferrets (Mustela nigripes). Sylvatic plague extirpates black-tailed prairie dog towns. We present a model to determine optimal control methods to sustain a black-tailed prairie dog town against the plague, including a recently developed vaccine. Our host submodel is a Susceptible, Exposed, Infectious, Vaccinated model, and our vector submodel is a Susceptible, Exposed, Early-Stage and Late-Stage Infectious model with questing and on-host vectors. Both submodels are hybrid ordinary differential and difference equation models to reflect the phenology of black-tailed prairie dogs. Our model suggests vaccination efforts can substantially outperform previous control methods (e.g., reactive insecticidal dusting). Our model suggests that a vaccine that provides eighteen months of immunity, administered annually, starting one year before an outbreak, can efficiently sustain a black-tailed prairie dog town against the plague. 